\title{
Apical Hypertrophic Cardiomyopathy: A Case Report
}

\author{
Ashraf Abugroun ${ }^{\mathrm{a}, \mathrm{b}}$, Fatima Ahmed ${ }^{\mathrm{a}}$, Daniel Vilchez ${ }^{\mathrm{a}}$, \\ Lalita Turaga $^{\mathrm{a}}$
}

\begin{abstract}
Apical hypertrophic cardiomyopathy $(\mathrm{ApHCM})$ is a rare variant of hypertrophic cardiomyopathy, characterized by a spade-like left ventricular cavity. A 58-year-old African-American female with past medical history of hypertension presented for evaluation of recurrent exertional chest tightness, palpitations and headache. Prior workup including multiple stress tests and angiogram was non-conclusive. Electrocardiogram (EKG) showed characteristic marked T-waves inversions in inferior leads and left ventriculography revealed left ventricle apical hypertrophy with spade like left ventricular cavity that was typical of Yamaguchi syndrome. This case highlights the rare incidence of the disease among African American as well as the challenging diagnostic and presentation features of the disease.
\end{abstract}

Keywords: Apical hypertrophic cardiomyopathy; Yamaguchi syndrome; African American; Coronary angiography; Ventriculography

\section{Introduction}

Apical hypertrophic cardiomyopathy (ApHCM) is a rare variant of hypertrophic cardiomyopathy, first described in Japan in 1976, characterized by a spade-like left ventricular cavity. ApH$\mathrm{CM}$ is more commonly seen in the Asian population; however, it has been well documented among many other population groups worldwide. Few cases were reported among African Americans. This case highlights the rare incidence of the disease among African Americans and the associated diagnostic challenge.

\section{Case Report}

A 58-year-old African-American female with past medical history of hypertension presented for evaluation of exertional chest tightness, palpitations and headache. Over preceding 3 years, patient had multiple hospital admissions with similar

Manuscript submitted October 6, 2017, accepted October 18, 2017

${ }^{a}$ Advocate Illinois Masonic Medical Center, Chicago, IL, USA

${ }^{b}$ Corresponding Author: Ashraf Abugroun, Advocate Illinois Masonic Medical Center, 836 W Wellington Ave., Chicago, IL 60657, USA.

Email: ashraf.abugroun@advocatehealth.com

doi: https://doi.org/10.14740/cr619w complaints, and she underwent extensive cardiac workup, including multiple stress tests as well as an angiogram, but a correct diagnosis was not reached. She had no family history of premature coronary artery disease or sudden cardiac death, and no history of tobacco use. Physical examination was within normal limits. Electrocardiogram (EKG) (Fig. 1) showed normal sinus rhythm, left ventricle hypertrophy and marked $\mathrm{T}$ waves inversions in leads II, III and aVF. Troponin was minimally elevated but stable at $0.008 \mathrm{ng} / \mathrm{mL}$, and other labs were unremarkable including normal thyroid-stimulating hormone and hemoglobin A1c. In lights of persistence of the symptoms, decision was made to take patient to cath lab. Coronary angiography (Fig. 2) showed preserved ejection fraction as well as angiographically normal coronary arteries. Left ventriculography revealed left ventricle apical hypertrophy with spade-like left ventricular cavity that was typical of the Japanese variant of asymmetrical apical hypertrophy known as "Japanese heart disease", or Yamaguchi syndrome.

\section{Discussion}

We report a case of a 58-year-old African American with ApHCM. ApHCM is a subtype of non-obstructive hypertrophic cardiomyopathy characterized by a spade-like left ventricular cavity. The disease is common in Japan where it was first reported [1]. In addition, ApHCM has been well documented among many other population groups worldwide [2-6]. Few cases were reported among African Americans [7, 8].

ApHCM has familial inheritance in an autosomal dominant pattern, sporadic forms of the disease caused by acquired genetic mutations of the sarcomere protein gene also exist [9]. Characteristic histological findings include edema, fibrosis, disorganization and bizarre nuclei in the myocardium [10]. The disease commonly presents on middle age and is most commonly seen in males [11] though in few cases, it was reported in both adolescents [12] and advanced age [13].

Common presenting symptoms include chest pain mimicking acute coronary syndrome [14], exertional dyspnea, palpitations, dizziness and fatigue [1]. Other reported features include syncope [15] and symptoms of heart failure [16].

ApHCM commonly has a benign course and is not associated with sudden cardiac death. Unfavorable outcomes include apical fibrosis, apical aneurysm formation, and heart failure. Life-threatening complications, such as myocardial infarction, arrhythmias, and stroke develop in around one-third of the patients, thus close follow-up is needed [17, 18]. Predictors of poor prognosis include advanced age, presence of hyperten- 


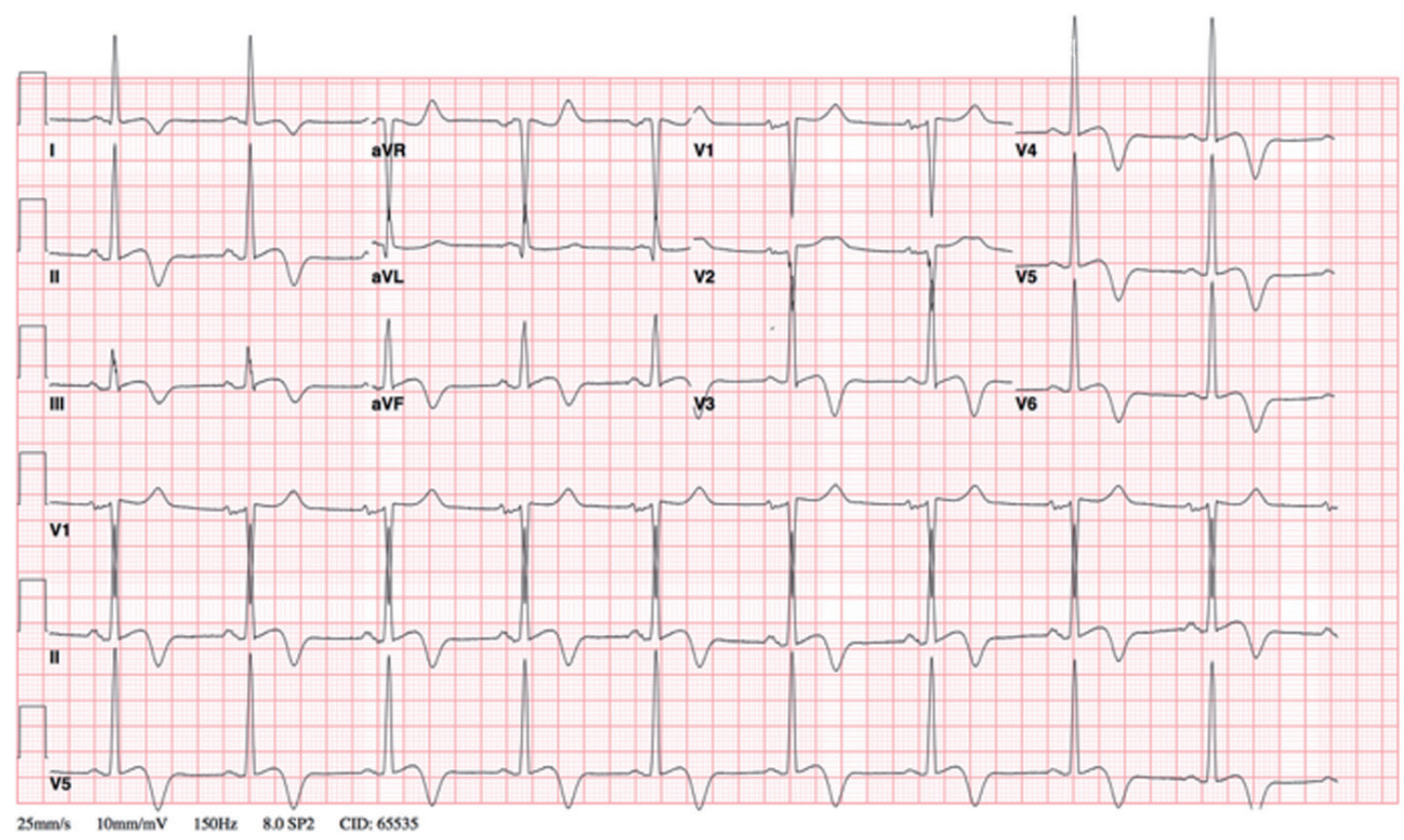

Figure 1. EKG shows normal sinus rhythm, left ventricle hypertrophy and marked T-wave inversions in leads II, III and aVF.

sion or diabetes, baseline atrial fibrillation, presence of echocardiographic findings including left atrial volume index, $\mathrm{Sa}$ velocity, and E/Ea ratio $[19,20]$ as well as cardiac magnetic resonance imaging finding including presence of apical aneurysm and extent of late gadolinium enhancement [21].

Typical EKG findings for hypertrophic cardiomyopathy include repolarization changes and giant $(>10 \mathrm{~mm})$, inverted $\mathrm{T}$ waves in the anterolateral leads [22]. The giant negative $\mathrm{T}$ wave can be used as an index of severity of ApHCM [23]. Diagnostic imaging modalities include contrast-enhanced echocardiography [24], ventriculography and cardiac magnetic resonance imaging [25]. Transthoracic echocardiography (TTE) is a helpful non-invasive tool in diagnosis of ApHCM; however, it is operator-dependent, and due to low familiarity and degree of suspicion, ApHCM is frequently missed by TTE [26]. In our patient, given high risk profile and high index of suspicion for non-ST elevation myocardial infarction, echocardiography was not performed and a decision was made to take the patient immediately to the cath lab. Surprisingly, the patient had normal coronaries and based on ventriculography a

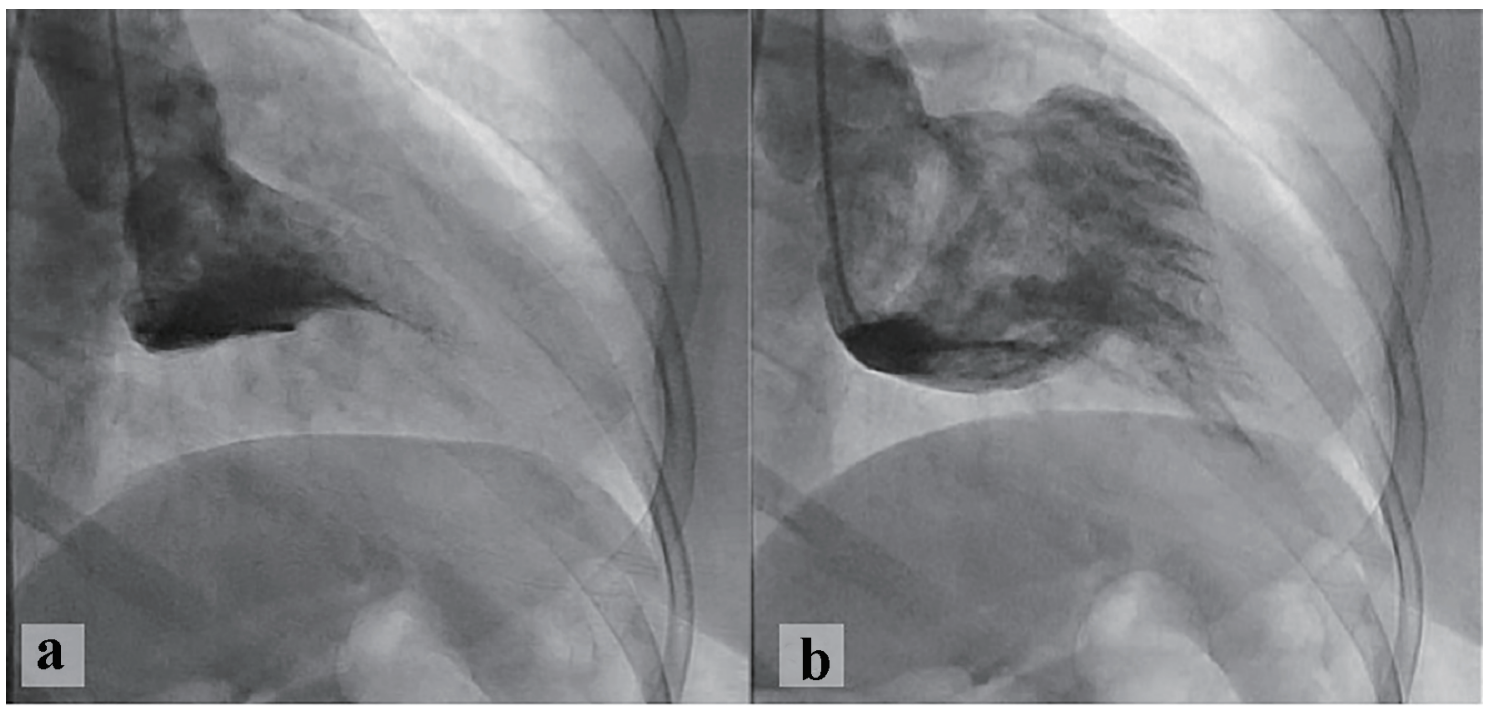

Figure 2. Left ventriculography revealed left ventricle apical hypertrophy with spade-like left ventricular cavity during systole (a) and diastole (b). 
diagnosis of ApHCM was made.

Treatment options for patients with symptomatic ApHCM are aimed towards decreasing heart rate and reduced left ventricular afterload through use of $\beta$-blockers, calcium-channel blockers, and angiotensin-converting enzyme inhibitors [27]. For patients with severe heart failure symptoms refractory to medical therapy, available options include heart transplant and apical myectomy [28].

\section{Conclusion}

With the increasing numbers of cases with ApHCM reported among non-Asian populations, physicians need to consider ApHCM in the evaluation of typical chest pain. Diagnosis of ApHCM is clinically challenging. Despite recurrent hospitalizations of the patient and repeated cardiac workup, the correct diagnosis remained elusive. Given its diverse presentation, understanding the unique EKG features with giant T-wave inversions provides the initial clues to making the diagnosis.

\section{References}

1. Yamaguchi H, Ishimura T, Nishiyama S, Nagasaki F, Nakanishi S, Takatsu F, Nishijo T, et al. Hypertrophic nonobstructive cardiomyopathy with giant negative $\mathrm{T}$ waves (apical hypertrophy): ventriculographic and echocardiographic features in 30 patients. Am J Cardiol. 1979;44(3):401-412.

2. Rovelli EG, Parenti F, Devizzi S. Apical hypertrophic cardiomyopathy of "Japanese type" in a Western European person. Am J Cardiol. 1986;57(4):358-359.

3. Kureshi SA, Malik SM, Hyder W. Apical hypertrophic cardiomyopathy in Pakistan: electrocardiographic, echocardiographic and myocardial scintigraphic features. J Pak Med Assoc. 1995;45(5):117-120.

4. Kranidis A, Filippatos G, Mavrogeni S, Kostopoulos K, Kappos K, Kardaras F, Fehske W, et al. Apical hypertrophic cardiomyopathy with unusual features in a Greek woman. Jpn Heart J. 1994;35(3):395-402.

5. Albanesi Filho FM, Castier MB, Lopes AS, Ginefra P. [Is the apical hypertrophic cardiomyopathy seen in one population in Rio de Janeiro city similar to that found in the East?]. Arq Bras Cardiol. 1997;69(2):117-123.

6. Kitaoka H, Doi Y, Casey SA, Hitomi N, Furuno T, Maron BJ. Comparison of prevalence of apical hypertrophic cardiomyopathy in Japan and the United States. Am J Cardiol. 2003;92(10):1183-1186.

7. Cassimatis DC, Atwood JE. Apical hypertrophic cardiomyopathy with giant negative T waves. Mayo Clin Proc. 2005;80(9):1245.

8. Smith M, Golwala H, Hanna EB. Apical hypertrophic cardiomyopathy with apical aneurysm in an AfricanAmerican male. J Cardiovasc Med (Hagerstown). 2012;13(11):771-774.

9. Arad M, Penas-Lado M, Monserrat L, Maron BJ, Sherrid M, Ho CY, Barr S, et al. Gene mutations in apical hypertrophic cardiomyopathy. Circulation. 2005;112(18):2805-
2811.

10. Nakanishi S, Nishiyama S, Nishimura S, Yamaguchi H, Matsuya S. [Histological features of apical hypertrophic cardiomyopathy]. J Cardiogr Suppl. 1985;6:3-11.

11. Eriksson MJ, Sonnenberg B, Woo A, Rakowski P, Parker TG, Wigle ED, Rakowski H. Long-term outcome in patients with apical hypertrophic cardiomyopathy. J Am Coll Cardiol. 2002;39(4):638-645.

12. Abdy NA, Valdes SO, Sorrell VL, Klewer SE, Barber BJ. Apical hypertrophic cardiomyopathy in an adolescent. Congenit Heart Dis. 2010;5(2):182-187.

13. Obeid AI, Maron BJ. Apical hypertrophic cardiomyopathy developing at a relatively advanced age. Circulation. 2001;103(11):1605.

14. Abdin A, Eitel I, de Waha S, Thiele H. Apical hypertrophic cardiomyopathy presenting as acute coronary syndrome. Eur Heart J Acute Cardiovasc Care. 2016;5(3):289-291.

15. Hiasa G, Hamada M, Kodama K, Watanabe S, Ohtsuka T, Ikeda $\mathrm{S}$, Hashida $\mathrm{H}$, et al. Apical hypertrophic cardiomyopathy associated with life-threatening paroxysmal atrial flutter with a slow ventricular response: a case report. Jpn Circ J. 2000;64(3):225-228.

16. Grabysa R. [Apical hypertrophic cardiomyopathy as a cause of cardiac insufficiency in an 84-year-old woman - a case report]. Kardiol Pol. 2008;66(2):179-182.

17. Abinader EG. Long-term outcome in patients with apical hypertrophic cardiomyopathy. J Am Coll Cardiol. 2002;40(4):837-838; author reply 838 .

18. Ridjab D, Koch M, Zabel M, Schultheiss HP, Morguet AJ. Cardiac arrest and ventricular tachycardia in Japanese-type apical hypertrophic cardiomyopathy. Cardiology. 2007;107(2):81-86.

19. Moon J, Shim CY, Ha JW, Cho IJ, Kang MK, Yang WI, Jang Y, et al. Clinical and echocardiographic predictors of outcomes in patients with apical hypertrophic cardiomyopathy. Am J Cardiol. 2011;108(11):1614-1619.

20. Klarich KW, Attenhofer Jost CH, Binder J, Connolly HM, Scott CG, Freeman WK, Ackerman MJ, et al. Risk of death in long-term follow-up of patients with apical hypertrophic cardiomyopathy. Am J Cardiol. 2013;111(12):1784-1791.

21. Hanneman K, Crean AM, Williams L, Moshonov H, James S, Jimenez-Juan L, Gruner C, et al. Cardiac magnetic resonance imaging findings predict major adverse events in apical hypertrophic cardiomyopathy. J Thorac Imaging. 2014;29(6):331-339.

22. Levis JT. ECG diagnosis: apical hypertrophic cardiomyopathy. Perm J. 2013;17(2):84.

23. Park SY, Park TH, Kim JH, Baek HK, Seo JM, Kim WJ, Cha KS, et al. Relationship between giant negative Twave and severity of apical hypertrophy in patients with apical hypertrophic cardiomyopathy. Echocardiography. 2010;27(7):770-776.

24. Acarturk E, Bozkurt A, Donmez Y. Apical hypertrophic cardiomyopathy: diagnosis with contrast-enhanced echocardiography - a case report. Angiology. 2003;54(3):373376.

25. van der Wall EE, Bax JJ, Schalij MJ. Detection of apical hypertrophic cardiomyopathy; which is the appro- 
priate imaging modality. Int $\mathrm{J}$ Cardiovasc Imaging. 2008;24(7):683-685.

26. Stainback RF. Apical hypertrophic cardiomyopathy. Tex Heart Inst J. 2012;39(5):747-749.

27. Gersh BJ, Maron BJ, Bonow RO, Dearani JA, Fifer MA, Link MS, Naidu SS, et al. 2011 ACCF/AHA guideline for the diagnosis and treatment of hypertrophic cardiomyopathy: a report of the American College of Cardiol- ogy Foundation/American Heart Association Task Force on Practice Guidelines. Circulation. 2011;124(24):e783831.

28. Schaff HV, Brown ML, Dearani JA, Abel MD, Ommen SR, Sorajja P, Tajik AJ, et al. Apical myectomy: a new surgical technique for management of severely symptomatic patients with apical hypertrophic cardiomyopathy. J Thorac Cardiovasc Surg. 2010;139(3):634-640. 